\title{
(2) OPEN ACCESS \\ Mucus barrier, mucins and gut microbiota: the expected slimy partners?
}

\author{
Paola Paone, Patrice D Cani
}

Metabolism and Nutrition Research Group, Louvain Drug Research Institute, Walloon Excellence in Life Sciences and BIOtechnology (WELBIO), UCLouvain, Université catholique de Louvain, Brussels, Belgium

\section{Correspondence to} Professor Patrice D Cani, Louvain Drug Research Institute, WELBIO, Metabolism and Nutrition, UCLouvain, Université catholique de Louvain, Avenue E. Mounier, 73 B1.73.11 B-1200, Brussels, Belgium; patrice.cani@uclouvain.be

Received 17 June 2020 Revised 16 July 2020 Accepted 18 July 2020 Published Online First 11 September 2020

\section{Check for updates}

\section{(c) Author(s) (or their} employer(s)) 2020. Re-use permitted under CC BY-NC. No commercial re-use. See rights and permissions. Published by BMJ.

To cite: Paone $\mathrm{P}$, Cani PD. Gut 2020;69:2232-2243.

\section{ABSTRACT}

The gastrointestinal tract is often considered as a key organ involved in the digestion of food and providing nutrients to the body for proper maintenance. However, this system is composed of organs that are extremely complex. Among the different parts, the intestine is viewed as an incredible surface of contact with the environment and is colonised by hundreds of trillions of gut microbes. The role of the gut barrier has been studied for decades, but the exact mechanisms involved in the protection of the gut barrier are various and complementary. Among them, the integrity of the mucus barrier is one of the first lines of protection of the gastrointestinal tract. In the past, this 'slimy' partner was mostly considered a simple lubricant for facilitating the progression of the food bolus and the stools in the gut. Since then, different researchers have made important progress, and currently, the regulation of this mucus barrier is gaining increasing attention from the scientific community. Among the factors influencing the mucus barrier, the microbiome plays a major role in driving mucus changes. Additionally, our dietary habits (ie, high-fat diet, low-fibre/high-fibre diet, food additives, pre- probiotics) influence the mucus at different levels. Given that the mucus layer has been linked with the appearance of diseases, proper knowledge is highly warranted. Here, we debate different aspects of the mucus layer by focusing on its chemical composition, regulation of synthesis and degradation by the microbiota as well as some characteristics of the mucus layer in both physiological and pathological situations.

\section{INTRODUCTION}

The mucosal integrity of the entire gastrointestinal (GI) tract is vital for maintaining health. This review intends to discuss one of the key components of gut barrier integrity, that is, the mucus, which cover the intestinal epithelial surface. The mucus is composed of many components: water (90\%-95\%), ${ }^{12}$ electrolytes, lipids (1\%-2\%), proteins and others. ${ }^{3}$ This mucus is a dilute, aqueous and viscoelastic secretion, thanks to specific mucus proteins that are called mucins and are the major structural and functional components present in the mucus at a concentration of $1 \%-5 \% .^{3}$

In this review, we will specifically focus our attention on the following questions: What are the major roles of mucins? What is their composition? How are they produced and secreted? How do gut microbes contribute to this regulation? What are the factors influencing their production and composition?

\section{Key messages}

- The gut mucus layer is vital for maintaining intestinal health.

- The regulation of the intestinal mucus barrier and glycobiology are very complex and dynamic systems still poorly understood.

- There is a complex bidirectional interaction between host glycans and gut microbes.

- Gut microbiota composition is an important factor contributing to the regulation of the intestinal mucus barrier function.

- Specific nutrients or potential next-generation beneficial bacteria can be used to prevent, improve or maintain a protective mucus layer.

Therefore, this review is divided into different subparts, starting with the mucus structure and organisation, then we discuss the difference between transmembrane mucins and gel-forming mucins, the variation in term of mucus composition between the small and the large intestine. After that, we focus on the role of the mucus, its bidirectional interaction with the gut microbiota, how external factors such as diet, specific probiotics or inflammatory bowel diseases (IBDs) may influence this dialogue or be influenced by these factors and eventually specifically impacting on health. Therefore, in this review, we will detail not only the different mechanisms and key molecular elements involved in the physiology of the mucus layer but also the impact of specific modifications.

\section{MUCUS STRUCTURE AND ORGANISATION}

Mucins are a family of large, complex, glycosylated proteins characterised by an important element, the 'mucin domain'. ${ }^{24}$ It consists of a protein core composed of sequences containing the amino acid residues proline (Pro), threonine (Thr) and serine (Ser) called PTS-rich sequences often repeated in tandem, in which the Ser and Thr are extensively O-glycosylated and confer a 'bottle brush'like conformation (figure 1). The amino acid Pro, instead, ensures that the structure of the mucins remains unfolded in the Golgi apparatus, allowing the O-glycosylation process (all the chemical steps are detailed in figures 1 and 2). ${ }^{15}$ More than $80 \%$ of the mucin mass is made up of O-glycans and $\mathrm{O}$-glycosylation is the main modification and type of glycosylation that affects mucins. ${ }^{167} \mathrm{O}$-glycosylation represents an important process allowing the creation of a glycan coat, hiding the protein core of the mucins and protecting it from endogenous 


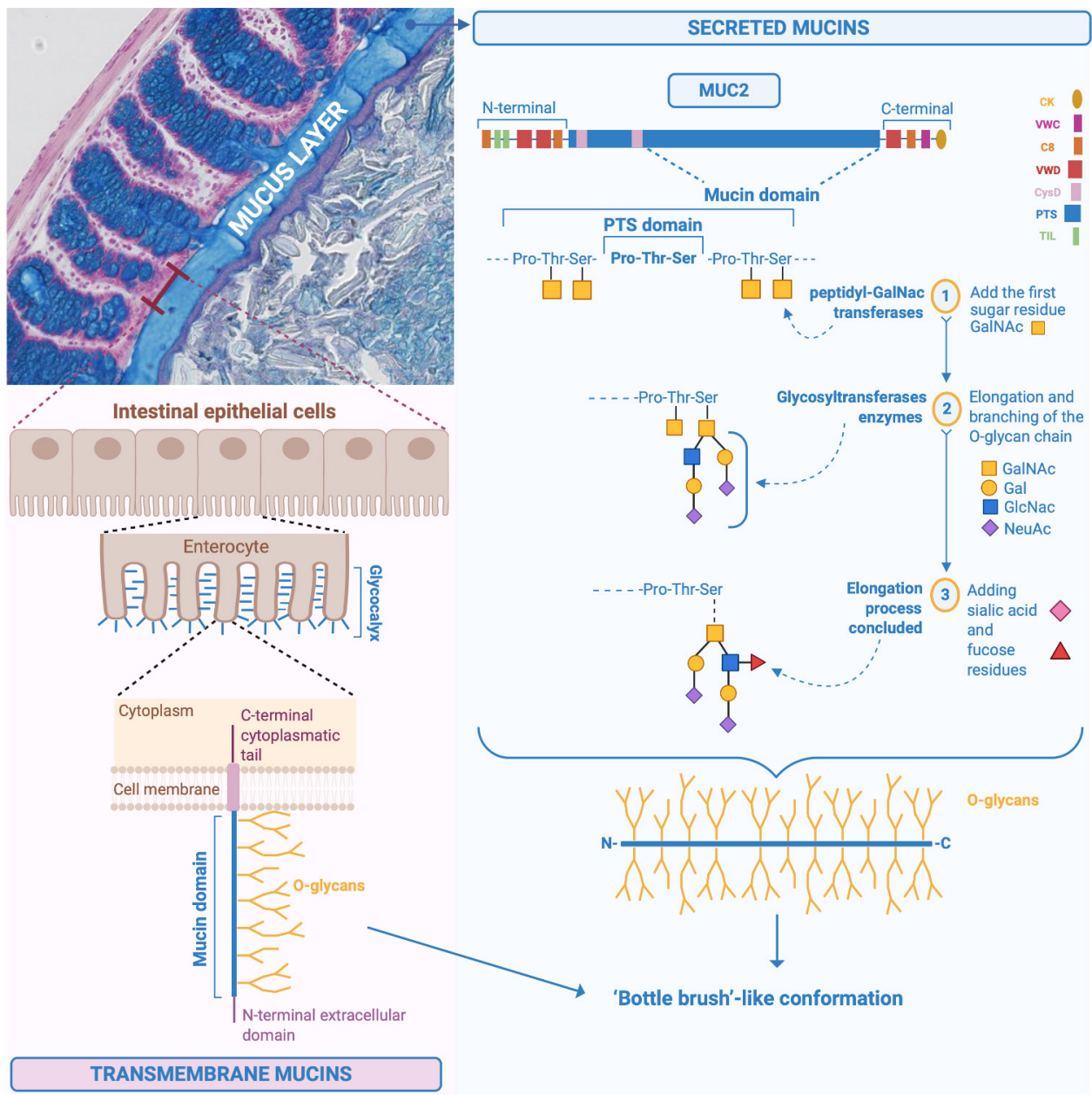

Figure 1 Chemical structure of MUC2 and synthesis of the mucus in the intestine. Specific structure of MUC2 including the different steps involved in the addition of the first-glycosylation made by the peptidyl-GalNAc transferases, that add the first sugar, the $\mathrm{N}$-acetylgalactosamine (GalNAc) residue, to the Ser and Thr of the PTS sequences. Subsequent elongation and branching of the 0-glycan chains with for instance GalNAc, galactose, $\mathrm{N}$-acetylglucosamine (GICNAc), $\mathrm{N}$-acetylneuraminic acid (NeuAc), and sulfate groups. Illustration of the transmembrane mucins on the surface of the enterocytes. Pro, proline; Ser, serine; Thr, threonine.

protease degradation, in addition to conferring the capacity to bind and be soluble in water and to form a gel. ${ }^{178}$ Glycosylation differs along the different regions of the digestive tract and among individuals, depending on the expression of glycosyltransferases, the state of health or disease and microbial colonisation. ${ }^{167}$ However, it has been shown that glycans are uniform among individuals in the distal part of the large intestine in humans. ${ }^{1}$ Moreover, among healthy individuals, it was observed that the MUC2 O-glycosylation profile was also qualitatively and quantitatively uniform. ${ }^{8}$

Finally, the mucins can be classified into two different types: transmembrane mucins and gel-forming mucins. ${ }^{2}$

\section{Transmembrane mucins}

Transmembrane mucins are synthetised and attached to the cell membrane of the enterocytes, covering their apical surface (figures 1 and 2). ${ }^{4}$ They are characterised by an $\mathrm{N}$-terminal extracellular domain, one or more mucin domains, a transmembrane domain and a C-terminal cytoplasmic tail, with phosphorylation sites involved in intracellular signal transduction (figure 1). ${ }^{246}$ Among the different mucins, MUC1/3/4/12/13/15/17/20 and 21 are found in the intestine at different locations (figure 3). ${ }^{149}$ The $\mathrm{N}$-terminal extracellular mucin domain of MUC3/12/17 reaches approximately $1 \mu \mathrm{m}$ from the tips of the enterocyte microvilli into the intestinal lumen, suggesting their participation in the formation of the densely glycosylated glycocalyx of enterocytes. MUC3/4/12/13 and 17 are always expressed, while MUC1 and MUC16 mucins are upregulated only in response to cancer and infection. ${ }^{2}$ These mucins do not contribute to the formation of mucus gels, and their function is primarily cell protection. They are likely sensors for the luminal milieu and involved in hostmicrobe interactions. ${ }^{68}$ Further insights into their specific functions and the presence of other possible types in the intestine are needed.

\section{Gel-forming mucins}

The gel-forming mucins (having gel-like properties) are secreted and synthetised by the goblet cells (figure 2) present in larger quantities in the crypt than on the villi in the small intestine and in the upper crypts in the colon (figures 2 and 3). ${ }^{2}{ }^{10}$ Among the gel-forming mucins, MUC6 is expressed in the duodenum in Brunner's glands, ${ }^{9}$ MUC5B is weakly expressed in the colon, and mucin 2 (MUC2/Muc2) is the best characterised secreted mucin of the GI tract. ${ }^{29}$ Of note, in the following text, mucins are denoted in uppercase when referring to humans (ie, MUC2), while for animals, only the first letter is capitalised (ie, Muc2). MUC2 is the main component of the intestinal mucus, present in the small and large intestine and forming the mucus skeleton 


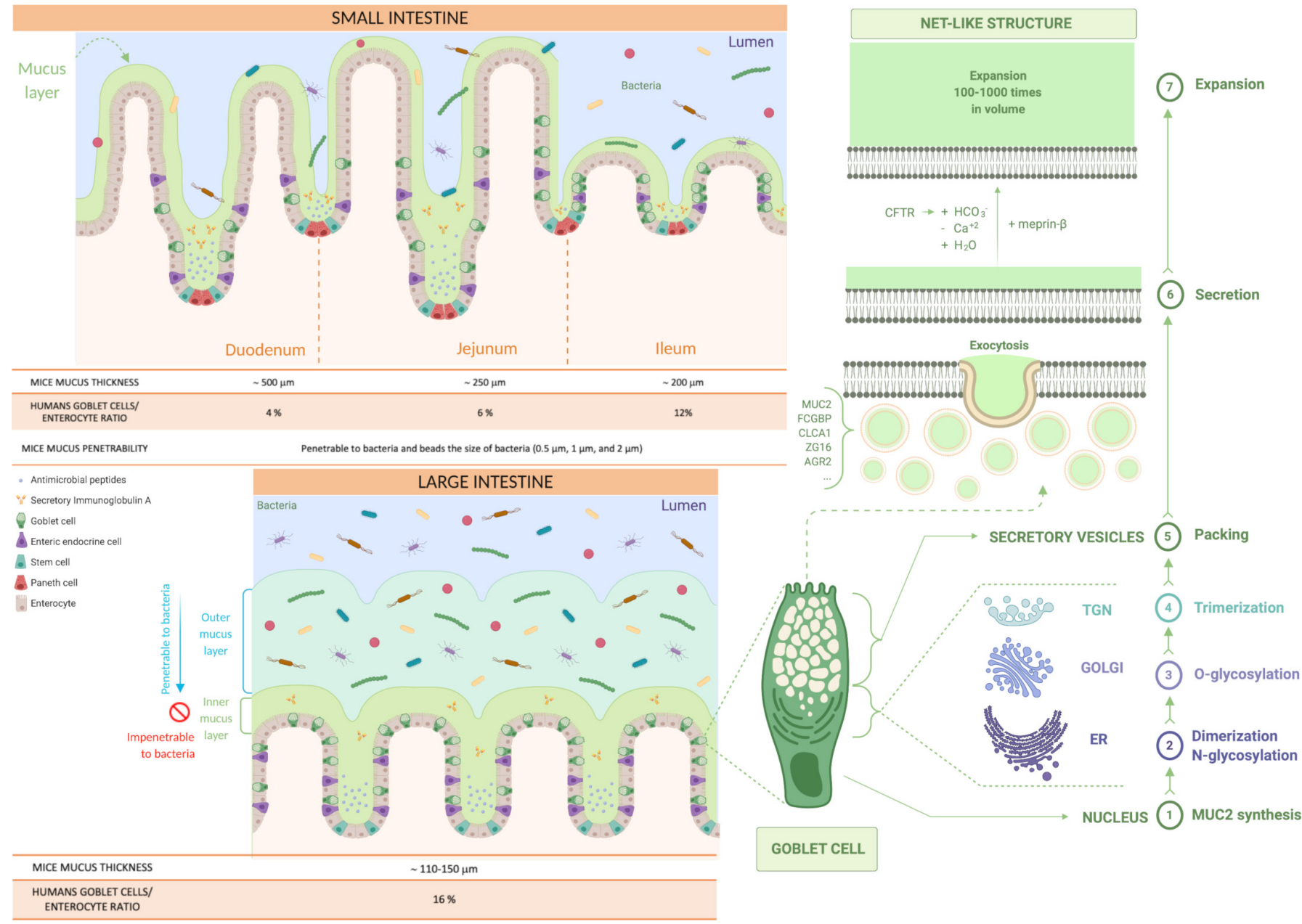

Figure 2 Production and distribution of the mucus in the small and the large intestine. Representation of the type of mucus layers in the small and the large intestine (inner and outer mucus layer). Identification of the steps involved in mucus production in the goblet cells and its secretion and expansion in the lumen (from 1 to 7). First, MUC2 monomers form dimers in the endoplasmic reticulum (ER), that are then 0-glycosylated in the Golgi apparatus and, in the trans-Golgi network (TGN), the MUC2 mucin dimers form trimers that are packed inside the secretory vesicles. The mucus secretion is a complex process; the goblet cells fill their secretory vesicles with Muc2 while migrating from the crypt bottom and contain other components, such as the Fc fragment of IgG-binding protein (FCGBP), chloride channel accessory 1 (CLCA1), zymogen granule protein 16 (ZG16) and anterior gradient homolog 2 (AGR2). The secretory vesicles extrude their content after their fusion with the apical membrane of the goblet cells, by exocytosis, allowing mucus secretion. Finally, the packed mucins must be exposed to several factors to expand, such as changes in $\mathrm{pH}$, $\mathrm{Ca}^{+2}$ concentration and bicarbonate ions $\left(\mathrm{HCO}_{3}{ }^{-}\right)$thanks to the cystic fibrosis transmembrane conductance regulator (CFTR) channel that will allow the mucins to form a net-like structure by expanding 100-1000 times in volume and binding water.

(figure 1), but as depicted in figure 3 , there are also specific mucins expressed only at specific locations of the GI tract. ${ }^{2}{ }^{10}$ It is important to note that the biosynthesis of the main component of the intestinal mucus, the MUC2 mucin, is highly complex and includes several steps detailed in figure 1 and figure 2. ${ }^{1258}$

The goblet cells fill their secretory vesicles with Muc2 while migrating from the crypt bottom ${ }^{5}$ and contain other mucus components, such as the Fc fragment of IgG-binding protein, chloride channel accessory 1 , zymogen granule protein 16 and anterior gradient homolog 2. ${ }^{10}$ The secretory vesicles extrude their content by exocytosis after fusion with the apical membrane. ${ }^{11}$ After secretion, to allow the packed mucins to properly expand, it is necessary to expose the mucin to an increase in $\mathrm{pH}$ and a decrease in calcium concentration. ${ }^{2}$ Bicarbonate ions $\left(\mathrm{HCO}_{3}{ }^{-}\right)$are involved in this process and are provided by the cystic fibrosis transmembrane conductance regulator channel, allowing the packed mucins to form a net-like structure, expanding 100-1000 times in volume, by binding water and creating a protective barrier (figure 2). ${ }^{1812}$

\section{Differences between the small intestine and the large intestine}

In humans, the goblet cell-to-enterocyte ratio changes along the intestinal tract, with an estimated percentage of goblet cells in the intestinal epithelium of approximately $4 \%$ in the duodenum, $6 \%$ in the jejunum, $12 \%$ in the ileum and $16 \%$ in the distal colon (figures 2 and 3). ${ }^{13}$ This gradual variation can be explained by the fact that, along the intestine, the proportion of goblet cells increases proportionally to the increase in the number of microorganisms. ${ }^{14}$

In the small intestine, the mucus is secreted in the crypts and the MUC2 mucin is anchored to the goblet cells after secretion, and for its detachment, the intervention of the protease meprin $\beta$ is necessary, which itself is released under the control of bacterial 


\begin{tabular}{|c|c|c|c|c|c|c|c|}
\hline MICE & \multicolumn{2}{|c|}{ GASTROINTESTINAL TRACT } & \multicolumn{5}{|c|}{ HUMANS } \\
\hline \multirow{2}{*}{$\begin{array}{c}\text { MUCUS } \\
\text { THICKNESS }\end{array}$} & \multirow[b]{6}{*}{ 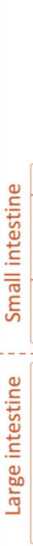 } & & \multirow{3}{*}{$\begin{array}{c}\text { GOBLET } \\
\text { CELLS/ } \\
\text { ENTEROCYTE } \\
\text { RATIO } \\
4 \%\end{array}$} & \multicolumn{4}{|c|}{ MUCINS } \\
\hline & & & & \multicolumn{2}{|r|}{ Secreted } & \multicolumn{2}{|c|}{ Transmembrane } \\
\hline$\sim 500 \mu \mathrm{m}$ & & & & $\begin{array}{l}\text { MUC2, } \\
\text { MUC6 }\end{array}$ & \multirow{4}{*}{$\begin{array}{l}\text { Functions: } \\
\text { - Source of } \\
\text { nutrients and } \\
\text { attachment } \\
\text { sites for the } \\
\text { gut microbiota } \\
\text { - Gel forming- } \\
\text { mucin } \\
\text { properties } \\
\text { - Diffusion } \\
\text { barrier }\end{array}$} & MUC1, 12, 15, 17 & \multirow{4}{*}{$\begin{array}{l}\text { Functions: } \\
\text { - Attachment sites } \\
\text { for the gut } \\
\text { microbiota } \\
\text { - Involved in host- } \\
\text { microbiota } \\
\text { interactions } \\
\text { - Glycocalyx } \\
\text { formation } \\
\text { - Cell protection } \\
\text { - Intracellular signal } \\
\text { transduction } \\
\text { - Sensors for the } \\
\text { luminal milieu }\end{array}$} \\
\hline$\sim 250 \mu \mathrm{m}$ & & Jejunum & $6 \%$ & MUC2 & & MUC1, 12, 15, 17 & \\
\hline$\sim 200 \mu \mathrm{m}$ & & lleum & $12 \%$ & MUC2 & & MUC1, 12, 15, 17 & \\
\hline$\sim 110-150 \mu \mathrm{m}$ & & Colon & $16 \%$ & $\begin{array}{l}\text { MUC2, } \\
\text { MUC5B }\end{array}$ & & $\begin{array}{c}\text { MUC3, 4, 12, 15, } \\
17,20,21\end{array}$ & \\
\hline
\end{tabular}

Figure 3 Mucus thickness and type of mucins in the intestinal tract in mice and humans. Description of the type of mucins and mucus thickness in the different parts of the $\mathrm{Gl}$ tract in both mice and humans, and their specific roles.

exposure (figure 2). ${ }^{2} 1012$ Moreover, the mucus is non-attached, experimentally easily removed (ie, easily aspired) and forms a discontinuous layer. ${ }^{8} 10$

It is also relatively porous and penetrable to different components as well as bacteria. ${ }^{12}$ Nevertheless, in physiological situations, no bacteria are in contact with intestinal epithelial cells, except at the tips of the villi or for segmented filamentous bacteria (SFB). ${ }^{17101516}$ It is worth mentioning that the mucus thickness varies along the different segments of the small intestinal tract but also according to the species considered. Although in animals the data present in the literature are still limited and with some discrepancies, it is proposed that the total mucus thickness estimated in mice is approximately $500 \mu \mathrm{m}$ in the duodenum, $250 \mu \mathrm{m}$ in the jejunum and $200 \mu \mathrm{m}$ in the ileum, ${ }^{17}$ whereas in rats, approximately $170 \mu \mathrm{m}$ in the duodenum, $124 \mu \mathrm{m}$ in the jejunum and $480 \mu \mathrm{m}$ in the ileum (figures 2 and 3 ). ${ }^{18}$ Regarding the mucus thickness in the small intestine of humans, considering the difficulty in obtaining these measurements in vivo, there are still few studies available; therefore, further investigations are required to obtain a complete picture of the reality.

In the large intestine, the mucus is organised in two different layers: the inner and the outer layer (figure 2). Although it was observed that they have almost identical protein profiles, ${ }^{8}$ there are significant differences between them. The inner mucus layer is continuously refilled by the MUC2 mucin, is anchored to the goblet cells and remains attached to the epithelium. ${ }^{78}{ }^{10}$ It has a stratified appearance due to its organisation in flat sheets, placed one below the other and forming a lamellar inner mucus layer (figure 2). ${ }^{45810}$ In mouse models, it has been seen that the inner mucus layer is not penetrable to bacteria, since it has pore sizes down to $0.5 \mu \mathrm{m} .^{10} 19$

At a certain distance $(\approx 50 \mu \mathrm{m}$ in mouse and $\approx 200 \mu \mathrm{m}$ in humans) from the epithelium, the inner mucus is converted by endogenous proteases into the outer mucus layer, forming a sharp border that separates the two (figure 2). ${ }^{10} 19$ The outer mucus layer expands four times in volume, maintaining the netlike structure and avoiding the dissolution of the mucus gel due to the disulfide bonds. ${ }^{2}$ This conversion seems to be dependent on the host rather than bacteria because germ-free (GF) mice also have an outer mucus layer. However, it is likely that bacteria can also contribute to it. ${ }^{8}$

Furthermore, in comparison to the inner mucus layer, the outer mucus layer is non-attached (also called 'loose' mucus) ${ }^{2}$ and so easily aspired, readily soluble in the chaotropic salt guanidinium chloride and it has a less well-defined outer border. ${ }^{5}$ Additionally, it has larger pores and is thus penetrable to bacteria or beads up to $0.5 \mu \mathrm{m}$ diameter, representing a habitat for commensal bacteria. ${ }^{5} 1020$

As in the small intestine, in the colon the mucus can be different depending on its location.

A recent study in rodents showed that there are differences in mucus organisation between the proximal colon and the distal colon; indeed, it has been shown that mucus is attached to the faecal pellet and is absent from the epithelial surface in the distal colon.

Moreover, the thickness is also variable, depending not only on the colon segment but also on the animal species considered (figure 3) and also differs according to the balance between the secretion and the degradation rate. ${ }^{21}$ Moreover, it has been estimated that the outer mucus layer has double the thickness of the inner mucus layer, and it seems that the thickness of the inner mucus layer is maintained constant over time. ${ }^{817}$

In the human colon, the thickness of the adherent mucus has also been measured thanks to surgically resected specimens, however, as already pointed out for the small intestine, there are strong limitations for a proper investigation of the large intestinal mucus layer thickness in both animal models and humans.

In conclusion for this part, it is important to highlight that most of the observations described have been obtained in animal models or by using in vitro human cells, further triggering the logical question, 'is this what is actually happening in vivo?'. Therefore, it is difficult to generalise these data to all populations. Finally, it has been proposed that the proportion of mucus-degrading bacteria increases when the diet is deprived specific dietary fibres, meaning that in absence of such dietary components the mucus may become the energy source for the gut microbiota. $^{22}$

Although this is already very complex, we cannot exclude that other important mucins, components and processes affecting the intestinal mucus remains to be discovered.

\section{MUCUS TURNOVER AND DEGRADATION}

The turnover of the intestinal mucus layer includes mucus synthesis, secretion and degradation, and it is a delicate process that needs to be regulated and balanced to ensure that mucus 
maintains an optimal protective function. It differs between the small and large intestine, indeed, in the upper intestinal tract, the turnover of the Muc2 mucin is slower in the goblet cells of the crypts than along the villi ${ }^{23}$ and in the colon, the surface goblet cells continuously secrete the inner mucus layer, while the goblet cells in the upper part of the colonic crypts secrete mucus in response to stress stimuli. In live murine distal colonic tissue, it has been suggested that the inner mucus layer is renewed every 1-2 hours. ${ }^{19}$ Moreover, spontaneous mucus growth is estimated at approximately $240 \mu \mathrm{m} /$ hour in humans and $100 \mu \mathrm{m} /$ hour in mice. ${ }^{17} 24$

Mucus degradation generally occurs due to physical disruption by mechanical shear forces of peristalsis and enzymatic cleavage by microbial enzymes, after which the mucus is transported with the intestinal content towards the rectum and finally excreted with the stool. ${ }^{78}$ In the colon, the conversion of MUC2 in the outer mucus layer allows bacteria to degrade mucin glycans. ${ }^{1}$

\section{THE ROLE OF MUCUS}

The intestinal mucus layer has a primary role in intestinal protection against mechanical, chemical and biological attacks and contributes to the maintenance of intestinal homeostasis. ${ }^{725}$ It creates a coat that covers the intestinal cells, protecting them from contact with external and toxic substances, digestive enzymes and bacteria. ${ }^{12}$ The important protective function of mucus stands out from its continuous secretion into the GI tract: approximately $10 \mathrm{~L}$ per day. ${ }^{21}$

The ability of mucin glycans to bind water confers mucus moisturising and lubricant properties, protecting the epithelial cells from dehydration and mechanical stress during the passage of luminal content and peristalsis forces. ${ }^{42125}$ Moreover, mucus also operates as a surface cleaner, removing debris and bacteria, through binding, collecting and flushing them away via intestinal flow. ${ }^{12}$ Among other functions, the intestinal mucus layer forms a diffusion barrier, in which small molecules, such as ions, water, nutrients and gases, can readily diffuse through it and reach the enterocytes. $^{21}$ The protective function of mucus is also due to its collaboration with the immune system. Indeed, mucus is a part of the innate mucosal intestinal barrier ${ }^{26}$ by being involved in the reduction of antigen exposure and bacteria to the immune system underlying the enterocytes, thus acting as a first line of immunological defence against possible harmful compounds. ${ }^{19}$ Several studies suggest that the mucus layer also has direct immunological effects due to their glycans, which are able to bind directly to immune cells through the lectin-like proteins found on the latter. ${ }^{219}$ Furthermore, MUC2 mucin enhances gut homoeostasis and oral tolerance, influencing dendritic cells and intestinal epithelial cells and MUC2 receptor complex suppresses inflammatory responses in dendritic cells. ${ }^{27}$

The mucus layer has an important role in the interaction with the gut microbiota, providing nutrients and attachment sites. ${ }^{28}$

The protective function of intestinal mucus differs between the small and large intestine. In the first, the mucus forms large pores and is penetrable to bacteria and other components, but despite this, in normal situations, the contact between bacteria and the epithelium is limited. ${ }^{129}$ Indeed, the continuous basal secretion of mucus forms a flow towards the lumen that, together with the presence of antibacterial agents (eg, lysozyme DMBT1, IgA, defensins, REG3 $\gamma$ and phospholipase A2-IIA) collaborates to keep bacteria away from the epithelial surface. $^{241930}$ These antibacterial agents are secreted by Paneth cells and enterocytes in the crypt bottom, are mixed with the secreted mucus ${ }^{21019}$ and are retained and diffused through the mucus, avoiding their rapid dilution and flow into the intestinal lumen. ${ }^{1021}$ Moreover, they diffuse slowly and form an antibacterial diffusion gradient, in which their concentration decreases from the epithelial cells to the intestinal lumen. ${ }^{2} 10$ By contrast, in the colon, the inner mucus layer is actually the first line of defence against bacteria, ${ }^{12}$ forming a size exclusion filter that separates bacteria from the epithelial cells and the immune system. ${ }^{5}$ This separation has been shown in humans from biopsy specimens. ${ }^{31}$

\section{BIDIRECTIONAL INTERACTION OF MUCUS AND THE GUT MICROBIOTA}

The gradient by which the gut microbiota distributes in the intestinal tract varies along its course; indeed, microbial density increases from the proximal to the distal gut, with the following numbers of microbial cells per gram of intestinal content: $10^{3}$ in the duodenum, $10^{4}$ in the jejunum, $10^{7}$ in the ileum and $10^{12}$ in the colon. ${ }^{32}$ Moreover, the microbial density increases from the epithelial cells towards the lumen, with the highest number of bacteria found in the latter, indeed few bacterial species are well adapted to adhere and reside in the mucus layer versus in the lumen. ${ }^{32}$ Except for this important function of adherence, the gut microbiota strongly contributes to modulate the intestinal mucus layer. The initial evidence of this observation came from studies performed in GF mice. For example, it was demonstrated that the gut microbiota is fundamental for the formation of a proper mucus layer and that the mucus in GF mice was different from that in conventionally raised (Convr) mice. First, in GF mice, the number of filled goblet cells was lower, the small intestinal mucus was anchored to the goblet cells and it could not be experimentally aspirated off. ${ }^{33}$

As previously mentioned, to release mucus from the small intestine, the action of the meprin $\beta$ enzyme is required, which in turn requires the presence of the gut microbiota to be activated, ${ }^{34}$ and mucus detachment is an important step for the maintenance of small intestinal homeostasis. ${ }^{2}$ Moreover, in the colon, the inner mucus layer was thinner and penetrable to bacteria, in comparison to Convr mice. Even the glycosylation profile was different between these two groups of mice, with more abundant core of 2 trisaccharide and two monosialylated core 2 isomers as the most obvious GF mucus differences. ${ }^{33}$

Additionally, bacterial products can be involved in these processes, considering that lipopolysaccharides (LPS) and peptidoglycans stimulated mucus secretion and restored mucus properties in GF mice to a similar extent as in conventionally raised animals. ${ }^{35}$ In conclusion, these studies observed that the protective mucus in the small and large intestines depends on the presence of bacteria or their components and metabolites to mature and develop its proper structure. ${ }^{33} 36$

Although these data are interesting, there are still numerous questions that remain unanswered. For instance, 'in which exact manner do the gut microbiota and related compounds contribute to the development of a proper mucus layer?' 'Is meprin $\beta$ activation the unique mechanism, or there are other underlying mechanisms that we still need to discover?'

Another very important question in this context is 'are there specific gut microbiota compositions or specific unique bacteria that are responsible for these effects?'

All these key questions require further investigations to fully understand how the gut microbiota and related molecules may influence intestinal mucus formation and degradation. 


\section{The gut microbiota composition influences mucus properties}

The fact that the gut microbiota composition plays a key role in influencing the intestinal mucus has been elegantly illustrated in a study that compared two mouse colonies that were genetically identical but were housed in different rooms of the same animal facility. The researchers discovered that, although the mice shared the same genetic background, raising them in different rooms was associated with different gut microbiota compositions, and consequently, with several differences in the intestinal mucus properties. In particular, the researchers discovered that one colony had a colonic mucus layer that was impenetrable by bacteria or by beads having the size of bacteria, while it was observed the contrary for the other colony. They demonstrated that the differences could be attributed to the gut microbiota composition because the mucus properties were transmitted after transplantation of caecal microbiota to GF mice. ${ }^{37}$ At this stage, it was suggested in their study that some bacteria (ie, Erysipelotrichi class, Allobaculum) have the ability to better induce a non-penetrable inner mucus layer, whereas others phyla (ie, Proteobacteria and TM7) have opposite effects. ${ }^{33}$

After this important observation, one of the key questions could be "What are the mechanisms by which the gut microbiota influences mucus composition?’

One possible answer is the pattern of expression of glycosyltransferases. Indeed, both the presence and the number of specific bacteria shape the glycan profile of the mucus and are directly associated with many glycosyltransferases for which the levels are increased in the presence of the gut microbiota. ${ }^{28} 30$ For example, it has been observed that some bacteria are able to induce the expression of host fucosyltransferases, which add L-fucose at the $\alpha-1,2$ position and sialyltransferases. ${ }^{30}$ Moreover, host bacterial communities are able to affect both MUC2 glycosylation and the glycosylation of transmembrane mucins. ${ }^{6}$

\section{The composition of the gut microbiota varies from the mucosal to the luminal side}

The composition of the gut microbiota undergoes changes from the mucosal to the luminal/faecal side, as observed in both humans and mice. ${ }^{38-42}$ It is known that luminal and mucosalassociated microbiota are different ecosystems with different microbial diversity and composition as well as metabolic and immunological functions. ${ }^{41}$ It has been shown in both humans and mice that many factors influence the bacterial distribution inside the gut. Among them, we can mention diet, the oxygen gradient, mucus, antimicrobials, microbial adherence and the host immune system as potentially the most important. ${ }^{38} 4344$ In particular, both intestinal oxygen and nutrient distribution are able to affect the gut microbiota composition of the faecal and mucosally adherent microbiota, suggesting that oxygen can favour or impede the growth of some microorganisms near the epithelial surface. ${ }^{4043}$

\section{Mucos-associated microbiota}

The intestinal mucus layer represents a natural and biological selective habitat for the gut microbiota, in which particular microorganisms, called 'mucus-associated microorganisms', can live, thanks to the presence of mucin glycans, which serve as attachment sites for bacteria, promoting their colonisation. ${ }^{2745}$

One of the major caveats in the field of the gut microbiota is that the exact composition of the mucosal microbiota remains poorly studied in contrast to the faecal gut microbiota. However, some studies suggest that in general, the phylum Firmicutes is higher in abundance in the mucus layer, than the phylum Bacteroidetes, in humans and rodents. ${ }^{14}{ }^{46}$ It has also been suggested that the mucosal side is enriched in Lachnospiraceae, Ruminococcaceae, Bifidobacterium bifidum, Bifidobacterium longum and the phylum Verrucomicrobia (represented by the mucus specialist Akkermansia muciniphila). Particularly, in humans, the presence of Lachnospiraceae, Enterobacteriaceae, Bacteroides, Eubacterium rectale, Faecalibacterium prausnitzii, Eubacterium cylindroides, Clostridium histolyticum, Clostridium lituseburense and A. muciniphila has been observed, while, in mice, SFB, Lactobacillus spp and A. muciniphila. ${ }^{46}$

However, there are also specific differences in the composition of the gut microbiota present in the outer or inner layer in the colon. Indeed, it is suggested that the colonic outer mucus layer is colonised by mucin-degrading bacteria such as Bacteroides acidifaciens (in mice), Bacteroides fragilis, Bifidobacteriaceae and A. muciniphila (in mice and humans). Despite the existing hypothesis that the inner mucus layer in the colon is devoid of bacteria in healthy individuals, some bacteria are able to penetrate the mucus and associate with the colonic crypts, as observed in healthy mice and humans. It has been shown that the communities able to associate with the colonic crypt are dominated principally by Acinetobacter spp and are usually rich in Proteobacteria. ${ }^{43}$ Moreover, recent studies in both mice and humans showed profound differences between faecal and inner mucus bacteria composition. The inner mucus layer was characterised by communities comprising 20\%-60\% Proteobacteria, a reduction in Bacteroidetes and a higher level of species $(\alpha)$-diversity compared with faecal samples. ${ }^{47}$ Finally, it is thought that the bacteria associated with the mucosa promote mucus secretion and eventually increase the mucus layer thickness. ${ }^{15}$

\section{Mucus-gut microbiota interactions}

Some of the factors influencing the presence of specific bacteria in the mucus layer rely on the chemistry of the latter. Indeed, it has been observed that the mucin glycosylation profile is able to influence the composition of mucus-associated bacteria, selecting specific species, and that mucin O-glycans promote homeostasis with host microbes. ${ }^{45}$ Both secreted and transmembrane mucins offer interaction and attachment sites to glycan-binding components of microorganisms. ${ }^{6}$ The mucus-binding capacity of the microorganism determines the ability to colonise the mucus, and it is important to increase the colonisation time ${ }^{46}$ Considering that each species is characterised by a core microbiota and that the glycan profile varies between species, it is suggested that only specific bacterial adhesins allow adaptation inside a specific host. ${ }^{5}$ Indeed, bacterial adhesion influences the composition of the gut microbiota, such as in the small intestine, where Helicobacter spp and SFB are able to adhere to and colonise the epithelial surface, attaching to the host glycans. ${ }^{43}$ Bacteria can interact and adhere to mucus and epithelial surface glycans through outermembrane proteins, lectins, adhesins, capsules and appendages such as pili, flagella and fimbriae. ${ }^{273243}$

In addition to supplying attachment sites, mucin glycans also serve as nutrients for microorganisms, so-called 'mucolytic bacteria, ${ }^{39}$ favouring their replication. ${ }^{17}$ Bacteria are able to digest glycans through their glycosidase enzymes, also called glycan-degrading enzymes, which are usually exoglycosidase type, that remove one sugar residue per time. ${ }^{52}$ It is suggested that up to $40 \%$ of the bacterial genomes encode these enzymes. However, the released glycan residues can be used by bacteria that digest them or by other members of the gut microbiota. ${ }^{28}$ Not all bacteria have all the enzymes needed to remove all mucin glycans, but only few of them, that can be considered mucolytic 
specialists (eg, A. muciniphila). ${ }^{12} 39$ Moreover, considering that the glycan profiles vary among different hosts, it is suggested that only specific microbial species have a repertoire of enzymes able to replicate in a specific host, further confirming the host's ability to select the gut microbiota. ${ }^{28}$ The glycan-degrading enzymes start to act from the non-reducing end of the mucin glycan chain, and when all the glycans are removed, the protein core of the mucin is degraded, and the entire mucin polymer network will finally be dissolved. ${ }^{5}$ This process contributes to MUC2 mucin and mucus degradation. ${ }^{148}$ Among the specific enzymes required for mucin degradation there are the glycoside hydrolases (such as sialidases, fucosidases, exo- $\beta-\mathrm{N}$-acetylglucosaminidases and endo- $\beta-\mathrm{N}$-acetylglucosaminidases, $\beta$-galactosidases, $\alpha-\mathrm{N}$ acetylglucosaminidases, $\alpha-\mathrm{N}$-acetylgalactosaminidases), sulfatases and proteases, ${ }^{7}$ belonging to the category of carbohydrate-active enzymes. ${ }^{9}$ While using glycans as an energy source, these enzymes generate short chain fatty acids (SCFAs) (acetate and butyrate) through the fermentation process. ${ }^{12} 49$ SCFAs are then absorbed and used by colonocytes to recover part of the energy spent for the expensive synthesis and secretion of MUC2 mucin ${ }^{49}$, further confirming a mutualist relationship between the host and the gut microbiota. ${ }^{49}$ It has been suggested that among the mucindegrading bacteria, there are mostly A. muciniphila, Bacteroides thetaiotaomicron, Bifidobacterium bifidum, Bacteroides fragilis, Ruminococcus gnavus and Ruminococcus torques. ${ }^{46}$ It is suggested that the proportion of mucus-degrading bacteria increases when the diet is deprived of fibre polysaccharides, considering that they are the main energy source for the gut microbiota. ${ }^{22}$ Indeed, some bacteria are able to adapt their nutritional preference, from mucin glycans to dietary carbohydrates, in relation to the types of nutrients available. For example, for human colonic anaerobes, the principal energy source is represented by fermentable carbohydrates, included in the category of dietary microbiotaaccessible carbohydrates (MACs), meaning the carbohydrates that are non-digested by the host enzymes but are used by the microbes as energy sources. Therefore, MACs may come from a large variety of dietary sources including non-digestible edible plant components, but also foodborne microbes, but that must be metabolised by the microbiota. Of note, the cellulose that humans are consuming is not metabolised by gut microbes and are not qualified "MACs". ${ }^{50}{ }^{51}$ In the case of food restriction or a lack of dietary MACs, these bacteria become dependent on host-derived endogenous MACs, represented by mucin glycans. ${ }^{251} \mathrm{~B}$. thetaiotaomicron is an example, considering its ability to change its carbohydrate-harvesting activities to host polysaccharides in relation to nutrient availability. ${ }^{50}$ However, this is in contrast with the mucin-degrading bacteria A. muciniphila, which is less abundant in a high-fat diet and in a diet poor in fibre. ${ }^{52}$ Moreover, considering that mucus degradation is a factor for the maintenance of a protective barrier and that some mucin-degrading bacteria (such as A. muciniphila) increase in healthy subjects and are associated with mucus thickness restoration, the question is 'why are some mucin-degrading bacteria beneficial for mucus maintenance and others are harmful?' It is very likely that there are other hidden mechanisms that we still need to discover. Finally, bacteria can use glycans not only as a source of energy but also to form new polymers that will be used as extracellular capsules. In this way, some bacteria can modify their capsule composition, promoting evasion to the immune system. ${ }^{53}$

\section{Commensal and pathogenic bacteria at the mucus layer}

Both commensal and pathogenic bacteria can degrade and use mucin glycans as an energy source and as attachment sites, promoting their replication and colonisation, but pathogenic bacteria are also able to cause infection. ${ }^{43}$ In normal situations, there are some mechanisms that avoid pathogen invasion and infection. For example, the intestinal epithelium can distinguish commensal and pathogenic microbiota by the presence of specific molecular patterns from microorganisms (eg, pattern recognition receptors), which are able to activate specific pathways that lead to inflammation in response to pathogen invasion. ${ }^{1454}$ Furthermore, beneficial bacteria can protect against pathogen invasion by increasing mucus production and occupying the binding sites available on the mucins, impeding pathogen adhesion. ${ }^{14}{ }^{43}$ Another protective mechanism is the limited motility in the mucus due to viscosity and flagellin immunogenicity. ${ }^{43}$ Nevertheless, there are some situations in which pathogenic bacteria can degrade and penetrate the protective mucus layer and subsequently adhere to and colonise intestinal epithelial cells, causing infection. ${ }^{25}$ To colonise and infect the intestinal epithelium, pathogenic bacteria need to degrade the mucus layer and penetrate inside it. This is possible thanks to the presence of mucin-degrading proteases, chemotaxis and flagella, which allow bacteria to move inside the mucus, to go against the mucus flow that normally pushes them towards the lumen and to adhere to the mucin glycans. $^{25}{ }^{25}$ Pathogenic bacteria may also modify mucus $\mathrm{pH}$, influencing mucus viscosity. For example, it is suggested that Helicobacter pylori increases the $\mathrm{pH}$, reducing the viscoelasticity of the mucus and increasing its motility. ${ }^{25}$ Some pathogenic bacteria are also able to use the products released from mucin degradation by commensal bacteria, such as free fucose and sialic acid, to support their proliferation inside the mucus. ${ }^{7}$ Finally, intestinal epithelium invasion can be permitted by the alteration of mucus protective barrier function by influencing the expression, synthesis and secretion of mucins. ${ }^{725}$

We will better explain how pathogens can alter the mucus layer and infect the intestine in the following chapter.

\section{HOW THE MUCUS LAYER CAN CHANGE AND WHAT ARE THE CONSEQUENCES}

The intestinal mucus layer is not static despite a basal and continuous level of secretion. Instead, there is an incredible number of processes discussed earlier in this review that are influenced by many factors. Indeed, it is important to note that mucin synthesis is also regulated at the transcriptional and epigenetic levels. For instance, transcription factors are able to bind to specific sites on MUC2 promoter. Numerous signalling pathways have been described as specifically targeting the transcriptional regulation of MUC2. They can be either linked to specific bacteria or microbial products such as LPS, flagellin, lipoteichoic acid (LPA), lipopeptide and are mostly acting through the activation of nuclear factor (NF)- $\mathrm{KB}$, which has been shown to have a binding site in the promoter of MUC2. Similarly, several inflammatory markers (eg, tumour necrosis factor- $\alpha$, Serum amyloid A3 and interleukins (IL)) are also activating the NF- $\mathrm{kB}$ pathway and stimulate the transcription of MUC2 (figure 4), ${ }^{55} 56$ whereas the activation of the Janus Kinase has inhibitory effects. ${ }^{57}$ Other pathways such as the cAMP-response element-binding protein and ATF1 are activated by the mitogen-activated protein kinases and $\mathrm{p} 38$ and have been described to regulate the expression of MUC2 (figure 4). ${ }^{58}$ Several IL such as IL-1 $\beta$, IL-4, IL-13 and L-22 have been shown to be involved in the regulation of goblet cell differentiation and mucin expression. ${ }^{10}$ Similar but also other additional very complex pathways have been shown to be 


\begin{tabular}{|c|c|c|c|c|}
\hline EFFECTORS & EXTERNAL & INTERNAL & $\begin{array}{l}\text { MUC2 EXPRESSION } \\
\text { and SECRETION }\end{array}$ & OUTCOMES \\
\hline $\begin{array}{l}\text { Gut bacteria } \\
\text { (PAMPs) }\end{array}$ & $\begin{array}{c}\text { LPA } \\
\text { LP } \\
\text { LPS } \\
\text { Flagellin } \\
\end{array}$ & $\begin{array}{c}\text { Activation of TLR-2, } \\
\text { TLR-4, TLR-5 } \\
\text { and the } \\
\text { NFF-B pathway }\end{array}$ & $\pi$ & \\
\hline \multirow[t]{2}{*}{$\begin{array}{c}\text { Cytokines or Inflammatory } \\
\text { markers }\end{array}$} & $\begin{array}{c}\text { SAA3 } \\
\text { IL-1 } \beta \\
\text { IL-4 } \\
\text { IL-10 } \\
\text { IL-13 } \\
\text { IL-22 } \\
\text { TNF- } \alpha \\
\end{array}$ & $\begin{array}{c}\text { JAK/STAT } \\
\text { NFK-B pathway }\end{array}$ & $\pi$ & $\begin{array}{c}\pi \text { mucus production } \\
\text { and barrier }\end{array}$ \\
\hline & TNF- $\alpha$ & JNK pathway & $\mathbf{y}$ & $\begin{array}{c}\text { mucus production } \\
\text { and barrier }\end{array}$ \\
\hline \multirow[t]{2}{*}{ Hormones / Neurotransmitters } & VIP & $\begin{array}{l}\text { CREB and ATF1 via the } \\
\text { MAPK and p38 pathway }\end{array}$ & $\pi$ & \multirow{4}{*}{$\begin{array}{l}7 \text { mucus production } \\
\text { and barrier }\end{array}$} \\
\hline & Acetylcholine & & $\pi$ & \\
\hline \multirow[t]{2}{*}{ Bioactive lipids } & Bile acids (DCA) & FXR / NFK-B pathway & $\pi$ & \\
\hline & PGE2 & CREB and ATF1 & $\pi$ & \\
\hline
\end{tabular}

Figure 4 Major effectors regulating the expression and the secretion of mucus. Principal effectors (ie, gut bacteria, cytokine and inflammatory markers, hormones, neurotransmitters and bioactive lipids acting on specific external (extracellular) and internal (intracellular signal transduction) signalling pathways influencing the expression (ie, gene expression and synthesis) and the secretion of the major mucin MUC2, and its impact on host. CREB, CAMP-response element (CRE)-binding protein; DCA, deoxycholic acid; EGF, epidermal growth factor; FXR, farnesoid receptor X; IL, interleukin; JAK, Janus kinase; JNK, c-Jun-N-terminal kinase; LP, lipopeptide; LPA, lipoteichoic acid; LPS, lipopolysaccharides; MAPK, mitogen-activated protein kinases; SAA, serum amyloid A; STAT, signal transducer and activator of transcription; TGF-alpha, transforming growth factor alpha; TLR, prostaglandin E2 (PGE2) Toll-like receptors; TNF, tumour necrosis factor; VIP, vasoactive intestinal peptide.

activated by different hormones, neurotransmitters (eg, vasoactive intestinal peptide, acetylcholine) or lipids (eg, bile acids, prostaglandins, butyrate) and eventually regulate the expression of MUC2 (for review ${ }^{145960}$ ) (figure 4). Finally, by investigating different type of colon cancers, studies have shown that epigenetic mechanisms such as methylation of $\mathrm{CpG}$ islands in the specific regions of MUC2, DNA methylation or histone modifications but also micro-RNAs contribute to the complex regulation of MUC2 expression. ${ }^{6162}$

Therefore, given that the expression, synthesis, secretion, degradation, glycosylation and structure of mucins, as well as mucus composition, viscosity, thickness and penetrability, can be changed in response to host factors (figure 4) and external factors (eg, pathogens, pre/probiotics, diet, food additives or contaminants and antibiotics), ${ }^{2} 71463$ this means that the regulation of the mucus barrier is a very complex system, and all the aforementioned factors can either positively or negatively affect the mucus layer. Obviously, understanding how the mucus layer can be regulated is of utmost importance.

\section{Mucus layer impairment}

'Mucus layer impairment' means a situation in which some of the following alterations can occur: a reduction in mucus synthesis, secretion, thickness and viscosity, an increase in mucus degradation and penetrability and an alteration of the mucin glycosylation profile and mucus composition. Hence, allowing commensal and pathogenic microorganisms to reach the intestinal epithelium, thereby leading to infection and inflammation, as described in many diseases. ${ }^{233}$

\section{Intestinal bowel disease}

The alteration of the mucus protective barrier plays a key role in the onset of IBD, such as Crohn's disease (CD) and ulcerative colitis (UC). ${ }^{152564}$

For example, it has been observed that in mice lacking MUC2 mucin, the colon was invaded by bacteria directly in contact with the epithelium and penetrating down into the crypts and epithelial cells. ${ }^{5}$ This bacterial invasion induces the response of the colonic immune system, characterised by inflammation, diarrhoea, rectal and colon prolapse, rectal bleeding and an increased risk of colon cancer development and spontaneous colitis. 5781065

Another example is the alteration of the mucin O-glycosylation profile. Indeed, it is suggested that mucin O-glycosylation influences mucus properties and penetrability and the composition of the associated microorganisms, and it is so essential for the intestinal mucus functions. Moreover, it has been observed that the mucin O-glycosylation profile is altered in IBD and colorectal cancer. ${ }^{7}$

In this context, it has been observed that in mice lacking the Core 1 glycosyltransferase, the MUC2 mucins had shorter $\mathrm{O}$-glycans and were subjected to faster degradation, and these mice developed severe colitis. ${ }^{56667}$ Another study demonstrated that all humans had uniform levels of MUC2 O-glycans in the sigmoid colon except the subjects with an inflamed colon. ${ }^{8}$ All these studies demonstrate how an altered host glycosylation profile is linked to several diseases.

During IBD, there is an increase in mucin-degrading bacteria, such as those from the Ruminococcus family, ${ }^{72}$ and during UC, the colonic mucus is characterised by a thinner layer due to decreased MUC2 production and secretion, altered mucus composition characterised by altered O-linked glycosylation of MUC2 and increased penetrability to bacteria, in patients with active inflammation. ${ }^{27122549}$ It has been observed that the glycosylation of MUC2 returned to normal after the remission of the patient. ${ }^{33}$ Finally, during CD, the mucus layer is thicker, suggesting an increase in MUC2 expression and goblet cell hyperplasia, but the structure of MUC2 is altered due to a reduction in the oligosaccharide chain length by $50 \%$, leading to a loss of mucus viscoelastic properties and consequently a loss of protective function. $^{25}$

Among the causes that induce an alteration of the mucus layer, we next focused on pathological microorganisms and some factors related to nutrition, such as a high-fat diet or western diet, a low-fibre diet and food additives (emulsifiers). 


\begin{tabular}{|c|c|}
\hline \multicolumn{2}{|c|}{ MUCUS REGULATION BY MICROORGANISMS AND METABOLITES } \\
\hline \multicolumn{2}{|c|}{ MICROORGANISMS } \\
\hline $\begin{array}{c}\text { Vibrio cholerae } \\
\text { Giardia lamblia } \\
\text { Entamoeba histolytica } \\
\text { Trichuris muris }\end{array}$ & - Induce mucins degradation \\
\hline $\begin{array}{c}\text { Listeria monocytogenes } \\
\text { Entamoeba histolytica } \\
\text { Nippostrongylus brasiliensis } \\
\text { Trichinella spiralis }\end{array}$ & $\begin{array}{ll}\text { - } & \text { Inhibit mucus production } \\
\text { - } & \text { Regulate Goblet cell function } \\
\text { - } & \text { Regulate mucin expression }\end{array}$ \\
\hline Lactobacillus spp. & $\begin{array}{ll} & \text { Stimulate MUC3 expression } \\
\text { - } & \text { Stimulate MUC2 } \text { production and secretion }\end{array}$ \\
\hline Bifidobacterium longum & - Restore mucus growth \\
\hline Lactobacillus reuteri & - Increase mucus layer thickness \\
\hline Akkermansia muciniphila & $\begin{array}{ll}\text { - } & \text { Restore/increase mucus layer thickness } \\
\text { - } & \text { Increase Goblet cell number }\end{array}$ \\
\hline \multicolumn{2}{|c|}{ MICROBIAL METABOLITES } \\
\hline SCFAs : acetate and butyrate & 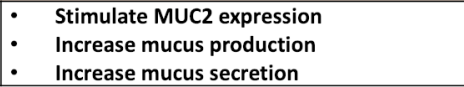 \\
\hline
\end{tabular}

Figure 5 Mucus regulation by specific micro-organisms and microbial metabolites. Overview of the impact of different microbial species, parasites and short chain fatty acids (SCFAs) on mucus properties, composition or functions.

\section{Pathological micro-organisms}

There are many ways by which pathogenic microorganisms are able to alter the intestinal mucus layer. One of these is their ability to degrade the mucins, as in the case of Vibrio cholerae and the protozoan Giardia lamblia in the small intestine and the proteases produced by Escherichia coli, the protozoan Entamoeba histolytica or the nematode Trichuris muris in the large intestine (figure 5). ${ }^{422}$

Through mucus degradation, the thickness of the mucus is decreased, and its penetrability is increased. This also allows infection by microorganisms that normally are, in theory, unable to cleave the mucus. ${ }^{39}$ Moreover, some species (eg, Listeria monocytogenes, E. histolytica, Nippostrongylus brasiliensis and Trichinella spiralis) inhibit mucus production and regulate, directly or indirectly, goblet cell function and mucin expression (figure 5). ${ }^{1425}$ The first reaction of the intestine to infections is an increase in the number of goblet cells and mucus synthesis and secretion, with the aim of moving away microorganisms, but during chronic infection, mucus hypersecretion induces a depletion of goblet cells, with a reduction in mucus synthesis and secretion and endoplasmic reticulum stress, eventually leading to inflammation. $^{2414}$

\section{Diet}

Among the causes associated with a disruption of the mucus layer, it has been shown that diet composition has an important role. ${ }^{68}$ For example, during high-fat diet feeding, there is an impairment in mucus production and secretion, an enrichment in barrier-disrupting species, and a decrease in the expression of the Ctfr gene in mouse ileal enterocytes, causing a reduction in viscosity and density of the mucus and an increase in intestinal permeability. ${ }^{6970}$ Furthermore, the mucus layer is altered during the development and presence of metabolic disorders, such as obesity and type 2 diabetes. ${ }^{5270-73}$

Similarly, western-style diet (WSD) (containing 40.5\% kcal from fat (41\% saturated, 52\% monounsaturated), 40.5\% from carbohydrates (sucrose 18\%, corn starch 16.0\%, maltodextrin $12.0 \%$, cellulose $4.0 \%(\mathrm{w} / \mathrm{v}))$ caused an alteration in the gut microbiota composition and a decrease in SCFA production associated with an impairment in the colonic inner mucus layer, including a reduction in the thickness and increased mucus penetrability (already after 3 days of a WSD). Moreover, in regions characterised by a western lifestyle, there is an increase in the incidence of UC, further suggesting an association of diet, mucus barrier function and IBD. ${ }^{49}$ The effects of these diets can be explained by a certain deficiency of dietary fibres, considering that the same results have been seen under a diet deprived of fibres (or dietary MACs), which was associated with an increased incidence of colitis and pathogen infections, while a regular consumption of dietary fibres (laboratory diet containing $\sim 15 \%$ of dietary fibres from minimally processed grains and plants) had a preventive effect, suggesting in this way that fibre plays a crucial role in contributing to the presence of a protective mucus barrier. $^{22} 517475$

In recent years, some food additives, such as emulsifiers, present in a very small quantity in food $(\sim 2 \%)$, have been shown to induce alterations in the gut microbiota composition associated with mucus layer impairment. Specifically, these alterations have been associated with a reduction in the mucus layer thickness ${ }^{76}$ and an increased gut penetrability, ${ }^{77}$ causing the erosion of the protective mucus barrier and increasing bacterial adherence to the epithelium. ${ }^{78}$ More importantly, all these effects are linked with intestinal inflammation and metabolic alterations. ${ }^{779}$

\section{Mucus layer enhancement}

Among the treatments and the factors that contribute to the prevention, improvement and maintenance of a protective mucus layer, we will briefly describe the following: probiotics, next-generation beneficial bacteria and microbial products and components.

\section{Probiotics, next-generation beneficial bacteria and microbia} products

Probiotics are live organisms that, administered in adequate amounts, confer a health benefit to the host. ${ }^{80}$ They might affect the mucus barrier, contributing, for example, to increase the expression of mucin genes, as in the case of the adherent Lactobacillus spp, which are able to stimulate MUC3 expression in human intestinal epithelial cells and MUC2 production and secretion. ${ }^{81} 82$ Other examples include the case of Bifidobacterium longum, which, when supplemented in mice after 4 weeks of feeding with a WSD restored mucus growth, ${ }^{83}$ and Lactobacillus reuteri, which showed a protective effect against dextran sulfate sodium treatment in mice, increasing the mucus layer thickness (figure 5). ${ }^{84}$

Finally, another key bacteria modifying the mucus layer is $A$. muciniphila. Indeed, during high-fat diet feeding the mice have a thinner inner mucus layer than the control group, while in mice treated with an high-fat diet plus viable $A$. muciniphila supplementation, the opposite effect is observed (ie, a restored mucus layer thickness) (figure 5). ${ }^{52}$ Interestingly, although this bacterium is known as a mucus degrader, supplementation with A. muciniphila increased number of goblet cells and the production of antimicrobial peptides, such as Reg3g and LyZ1. Altogether, these findings suggest that A. muciniphila communicates with host cells and eventually stimulates the production of mucus (figure 5). ${ }^{5285-88}$ It is worth noting that this important effect on the number of goblet cells and the reinforcement of the gut barrier was also observed when A. muciniphila was killed by pasteurisation but not when killed by autoclaving. ${ }^{89}$ Among the potential mechanisms, it has been shown that $A$. muciniphila expresses specific proteins on its outer membrane, such as the protein Amuc_1100. This protein is resistant to the heating process and remain in the active conformation. ${ }^{89}$ Interestingly, treating mice with only this protein and without 
the bacteria also replicated the effects of the bacteria on the increased number of goblet cells and the reinforcement of the gut barrier. ${ }^{89}$ Strikingly, this protein binds and activates TLR2, thereby possibly explaining the effects of the bacteria on both the regulation of immunity and the reinforcement of the gut barrier (figure 4). Therefore, suggesting that the viability of the bacteria is not required to observe the beneficial effects. Altogether, this suggests that the regulation of mucus layer thickness by A. muciniphila is likely more complex than the 'simple' active degradation and utilisation of mucus glycans by this bacteria and also involves specific microbial compounds. Interestingly, in addition to the data obtained in rodents, it has been shown that obese and type 2 diabetic subjects were also characterised by a lower abundance of A. muciniphila. ${ }^{80}{ }^{90} \mathrm{In}$ a first proofof-concept pilot human intervention in subjects with metabolic syndrome, we recently confirmed that $A$. muciniphila improved metabolism (ie, improved insulin sensitivity, lower inflammation), together with reduced plasma LPS levels, thereby suggesting a reinforcement of the gut barrier. ${ }^{91}$

Altogether, this specific example is additional evidence suggesting an association of the gut microbiota, the mucus layer/ gut barrier and diseases.

The example of A. muciniphila and its components is evident for bacteria considered mucus specialists. However, other bacteria can influence the mucus by themselves but also by specific products and components, such as SCFAs, LPSs, flagellin and LPA (figure 4). For example, it has been shown that mucosalassociated bacteria promote mucus secretion and increase mucus layer thickness through the release of microbe-associated molecular patterns (MAMPs) and the production of SCFAs. ${ }^{15}$ It has also been observed that SCFAs, such as acetate and butyrate, stimulate MUC2 expression in intestinal epithelial cells and increase mucus production and secretion (figure 5). ${ }^{25} 9293$ Moreover, among the bacterial components, purified flagellin from gram-negative bacteria, LPA from gram-positive bacteria and LPS are able to upregulate mucin expression, and the latter also increase mucus secretion by goblet cells (figure 4). ${ }^{7148194}$

\section{CONCLUSIONS}

In conclusion, in this review, we have covered different complementary aspects of the mucus barrier by covering the mucus chemistry, production, secretion and degradation, and the various factors involved in the modification of the mucus layer status. Although the mucus barrier remains a neglected component of gut barrier function in many studies, increasing attention has been paid to the different ways to approach it, ranging from a simple investigation of mucus thickness to an investigation of its detailed composition, turnover and penetrability as well as the regulation of the number of goblet cells and their differentiation. To have an overall and more accurate vision, researchers should not rely only on one factor characterising the mucus, such as its thickness, considering that, for example, its increase is often associated with a mucus barrier improvement, but it can also hide the beginning of pathogenic infections.

Moreover, the mucus layer not only acts as an important factor for protecting the host against microbial invaders but also contributes to the mutualism between the host and microbes. Many diseases are associated with the alteration of the mucus layer thickness, but it is still difficult to identify whether this effect is a cause or a consequence of the disease. Additionally, recent evidence suggests that specific gut microbes contribute to the regulation of the mucus barrier and eventually intestinal and host health (eg, A. muciniphila); however, there are still many gaps that need to be filled to understand the sophisticated mechanisms hidden behind these slimy neglected partners.

Twitter Paola Paone @Paola_9229 and Patrice D Cani @MicrObesity

Acknowledgements Figure 1 and 2 are created with BioRender.com

Contributors PP and PDC conceived and drew the figures. PP and PDC have all contributed to the design and the writing of the review.

Funding PDC is a senior research associate at FRS-FNRS (Fonds de la Recherche Scientifique), Belgium. He is supported by the Fonds Baillet Latour (Grant for Medical Research 2015) and the Fonds de la Recherche Scientifique (FNRS, FRFSWELBIO: WELBIO-CR-2019C-02R, and EOS programme no.30770923). PDC and PP received funding from the European Union's Horizon 2020 research and innovation programme (H2020 MSCA Sweet Crosstalk project under grant agreement No 814102).

Competing interests PDC is an inventor of patent applications dealing with the use of Akkermansia muciniphila and its components in the context of obesity and related disorders. PDC is cofounder of A-Mansia Biotech SA.

Patient consent for publication Not required.

Provenance and peer review Commissioned; externally peer reviewed.

Open access This is an open access article distributed in accordance with the Creative Commons Attribution Non Commercial (CC BY-NC 4.0) license, which permits others to distribute, remix, adapt, build upon this work non-commercially, and license their derivative works on different terms, provided the original work is properly cited, appropriate credit is given, any changes made indicated, and the use is non-commercial. See: http://creativecommons.org/licenses/by-nc/4.0/.

ORCID iD

Patrice D Cani http://orcid.org/0000-0003-2040-2448

\section{REFERENCES}

1 Hansson GC. Mucins and the microbiome. Annu Rev Biochem 2020.

2 Johansson MEV, Hansson GC. Immunological aspects of intestinal mucus and mucins. Nat Rev Immunol 2016;16:639-49.

3 Bansil R, Turner BS. The biology of mucus: composition, synthesis and organization. Adv Drug Deliv Rev 2018;124:3-15.

4 Johansson MEV, Sjövall H, Hansson GC. The gastrointestinal mucus system in health and disease. Nat Rev Gastroenterol Hepatol 2013;10:352-61.

5 Johansson MEV, Ambort D, Pelaseyed T, et al. Composition and functional role of the mucus layers in the intestine. Cellular and Molecular Life Sciences 2011:68:3635-41.

6 Pelaseyed T, Hansson GC. Membrane mucins of the intestine at a glance. J Cell Sci 2020;133:jes240929.

7 Etienne-Mesmin L, Chassaing B, Desvaux M, et al. Experimental models to study intestinal microbes-mucus interactions in health and disease. FEMS Microbiol Rev 2019;43:457-89.

8 Johansson MEV, Larsson JMH, Hansson GC. The two mucus layers of colon are organized by the MUC2 mucin, whereas the outer layer is a legislator of hostmicrobial interactions. Proc Natl Acad Sci U S A 2011;108:4659-65.

9 Tailford LE, Crost EH, Kavanaugh D, et al. Mucin glycan foraging in the human gut microbiome. Front Genet 2015:6:81.

10 Birchenough GMH, Johansson MEV, Gustafsson JK, et al. New developments in goblet cell mucus secretion and function. Mucosal Immunol 2015;8:712-9.

11 Forstner G. Signal transduction packaging and secretion of mucins. Annu Rev Physiol 1995;57:585-605.

12 Hansson GC. Mucus and mucins in diseases of the intestinal and respiratory tracts. J Intern Med 2019;285:479-90.

13 König J, Wells J, Cani PD, et al. Human intestinal barrier function in health and disease. Clin Trans/ Gastroenterol 2016;7:e196.

$14 \mathrm{Kim}$ YS, Ho SB. Intestinal goblet cells and mucins in health and disease: recent insights and progress. Curr Gastroenterol Rep 2010;12:319-30.

15 Wells JM, Brummer RJ, Derrien M, et al. Homeostasis of the gut barrier and potential biomarkers. Am J Physiol Gastrointest Liver Physiol 2017:312:G171-93.

16 Hedblom GA, Reiland HA, Sylte MJ, et al. Segmented Filamentous Bacteria Metabolism Meets Immunity. Front Microbiol 2018;9:9.

17 Ermund A, Schütte A, Johansson MEV, et al. Studies of mucus in mouse stomach, small intestine, and colon. I. Gastrointestinal mucus layers have different properties depending on location as well as over the Peyer's patches. Am J Physiol Gastrointest Liver Physiol 2013:305:G341-7.

18 Atuma C, Strugala V, Allen A, et al. The adherent gastrointestinal mucus gel layer: thickness and physical state in vivo. Am J Physiol Gastrointest Liver Physiol 2001;280:G922-9.

19 Pelaseyed T, Bergström JH, Gustafsson JK, et al. The mucus and mucins of the goblet cells and enterocytes provide the first defense line of the gastrointestinal tract and interact with the immune system. Immunol Rev 2014;260:8-20. 
20 Johansson MEV, Phillipson M, Petersson J, et al. The inner of the two Muc2 mucindependent mucus layers in colon is devoid of bacteria. Proc Natl Acad Sci U S A 2008; 105:15064-9.

21 Cone RA. Barrier properties of mucus. Adv Drug Deliv Rev 2009;61:75-85.

22 Martens EC, Neumann M, Desai MS. Interactions of commensal and pathogenic microorganisms with the intestinal mucosal barrier. Nat Rev Microbiol 2018;16:457-70.

23 Schneider H, Pelaseyed T, Svensson F, et al. Study of mucin turnover in the small intestine by in vivo labeling. Sci Rep 2018;8:5760.

24 Gustafsson JK, Sjovall H, Hansson GC. Ex vivo measurements of mucus secretion by colon explants. Methods Mol Biol 2012;842:237-43.

25 Cornick S, Tawiah A, Chadee K. Roles and regulation of the mucus barrier in the gut. Tissue Barriers 2015:3:e982426.

26 Corfield AP. Mucins: a biologically relevant glycan barrier in mucosal protection. Biochim Biophys Acta 1850;2015:236-52.

27 Shan M, Gentile M, Yeiser JR, et al. Mucus enhances gut homeostasis and oral tolerance by delivering immunoregulatory signals. Science 2013;342:447-53.

28 Arike L, Hansson GC. The densely 0-glycosylated MUC2 mucin protects the intestine and provides food for the commensal bacteria. J Mol Biol 2016:428:3221-9.

29 Camilleri M. Leaky gut: mechanisms, measurement and clinical implications in humans. Gut 2019;68:1516-26.

30 Schroeder BO. Fight them or feed them: how the intestinal mucus layer manages the gut microbiota. Gastroenterology Report 2019;7:3-12.

31 Johansson MEV, Gustafsson JK, Holmén-Larsson J, et al. Bacteria penetrate the normally impenetrable inner colon mucus layer in both murine colitis models and patients with ulcerative colitis. Gut 2014:63:281-91.

32 Sommer F, Bäckhed F. The gut microbiota - masters of host development and physiology. Nat Rev Microbiol 2013:11:227-38.

33 Johansson MEV, Jakobsson HE, Holmén-Larsson J, et al. Normalization of host intestinal mucus layers requires long-term microbial colonization. Cell Host Microbe 2015; 18:582-92.

34 Schütte $A$, Ermund A, Becker-Pauly $C$, et al. Microbial-induced meprin $\beta$ cleavage in MUC2 mucin and a functional CFTR channel are required to release anchored smal intestinal mucus. Proc Natl Acad Sci U S A 2014;111:12396-401.

35 Petersson J, Schreiber $\mathrm{O}$, Hansson GC, et al. Importance and regulation of the colonic mucus barrier in a mouse model of colitis. Am J Physiol Gastrointest Liver Physiol 2011:300:G327-33.

36 Rodríguez-Piñeiro AM, Johansson MEV. The colonic mucus protection depends on the microbiota. Gut Microbes 2015:6:326-30.

37 Jakobsson HE, Rodríguez-Piñeiro AM, Schütte A, et al. The composition of the gut microbiota shapes the colon mucus barrier. EMBO Rep 2015;16:164-77.

38 Eckburg PB, Bik EM, Bernstein CN, et al. Diversity of the human intestinal microbia flora. Science 2005;308:1635-8.

39 Li H, Limenitakis JP, Fuhrer T, et al. The outer mucus layer hosts a distinct intestinal microbial niche. Nat Commun 2015;6:8292.

40 Albenberg L, Esipova TV, Judge CP, et al. Correlation between intraluminal oxygen gradient and radial partitioning of intestinal microbiota. Gastroenterology 2014:147:1055-63.

41 Ringel Y, Maharshak N, Ringel-Kulka T, et al. High throughput sequencing reveals distinct microbial populations within the mucosal and luminal niches in healthy individuals. Gut Microbes 2015;6:173-81

42 Van den Abbeele P, Belzer C, Goossens M, et al. Butyrate-producing Clostridium cluster XIVa species specifically colonize mucins in an in vitro gut model. Isme J 2013;7:949-61.

43 Donaldson GP, Lee SM, Mazmanian SK. Gut biogeography of the bacterial microbiota. Nat Rev Microbiol 2016;14:20-32.

44 Powell N, Pantazi E, Pavlidis P, et al. Interleukin-22 orchestrates a pathological endoplasmic reticulum stress response transcriptional programme in colonic epithelia cells. Gut 2020:69:578-90.

45 Bergstrom KSB, Xia L. Mucin-type 0-glycans and their roles in intestinal homeostasis. Glycobiology 2013:23:1026-37.

46 Ouwerkerk JP, de Vos WM, Belzer C. Glycobiome: bacteria and mucus at the epithelial interface. Best Pract Res Clin Gastroenterol 2013:27:25-38.

47 Chassaing B, Gewirtz AT. Identification of inner mucus-associated bacteria by laser capture microdissection. Cell Mol Gastroenterol Hepatol 2019;7:157-60.

48 Li H, Limenitakis JP, Ganal SC, et al. Penetrability of the inner mucus layer: who is out there? EMBO Rep 2015;16:127-9.

49 Birchenough G, Schroeder BO, Bäckhed F, et al. Dietary destabilisation of the balance between the microbiota and the colonic mucus barrier. Gut Microbes 2019:10:246-50.

50 Sonnenburg JL, Xu J, Leip DD, et al. Glycan foraging in vivo by an intestine-adapted bacterial symbiont. Science 2005:307:1955-9.

51 Sonnenburg ED, Sonnenburg JL. Starving our microbial self: the deleterious consequences of a diet deficient in microbiota-accessible carbohydrates. Cell Metab 2014;20:779-86.

52 Everard A, Belzer C, Geurts L, et al. Cross-talk between Akkermansia muciniphila and intestinal epithelium controls diet-induced obesity. Proc Natl Acad Sci U S A 2013; 110:9066-71.
53 Martens EC, Roth $\mathrm{R}$, Heuser JE, et al. Coordinate regulation of glycan degradation and polysaccharide capsule biosynthesis by a prominent human gut symbiont. J. Biol. Chem. 2009;284:18445-57

54 Fukata $\mathrm{M}$, Arditi $\mathrm{M}$. The role of pattern recognition receptors in intestinal inflammation. Mucosal Immunol 2013;6:451-63.

55 Tashiro M, Iwata A, Yamauchi M, et al. The N-terminal region of serum amyloid A3 protein activates NF- $\kappa B$ and up-regulates MUC2 mucin mRNA expression in mouse colonic epithelial cells. PLoS One 2017:12:e0181796.

56 Iwashita J, Sato Y, Sugaya H, et al. mRNA of MUC2 is stimulated by IL-4, IL-13 or TNF- $\alpha$ through a mitogen-activated protein kinase pathway in human colon cancer cells. Immunol Cell Biol 2003;81:275-82.

57 Ahn D, Crawley S, Hokari R, et al. TNF-alpha activates MUC2 transcription via NFkappaB but inhibits via JNK activation. Cell Physiol Biochem 2005;15:029-40.

58 Hokari R, Lee H, Crawley SC, et al. Vasoactive intestinal peptide upregulates MUC2 intestinal mucin via CREB/ATF1. Am J Physiol Gastrointest Liver Physiol 2005:289:G949-59.

59 Yamashita MSdeA, Melo EO. Mucin 2 (MUC2) promoter characterization: an overview. Cell Tissue Res 2018:374:455-63.

60 Herath M, Hosie S, Bornstein JC, et al. The role of the gastrointestinal mucus system in intestinal homeostasis: implications for neurological disorders. Front Cell Infect Microbiol 2020;10:248

61 Okudaira K, Kakar S, Cun L, et al. MUC2 gene promoter methylation in mucinous and non-mucinous colorectal cancer tissues. Int J Oncol 2010;36:765-75.

62 Yamada N, Kitamoto S, Yokoyama $\mathrm{S}$, et al. Epigenetic regulation of mucin genes in human cancers. Clin Epigenetics 2011;2:85-96.

63 Laudisi F, Di Fusco D, Dinallo V, et al. The food additive maltodextrin promotes endoplasmic reticulum Stress-Driven mucus depletion and exacerbates intestinal inflammation. Cell Mol Gastroenterol Hepatol 2019:7:457-73.

64 van der Post S, Jabbar KS, Birchenough G, et al. Structural weakening of the colonic mucus barrier is an early event in ulcerative colitis pathogenesis. Gut 2019;68:2142-51.

65 Van der Sluis M, De Koning BAE, De Bruijn ACJM, et al. Muc2-deficient mice spontaneously develop colitis, indicating that MUC2 is critical for colonic protection. Gastroenterology 2006;131:117-29.

66 Bergstrom K, Fu J, Johansson MEV, et al. Core 1- and 3-derived 0-glycans collectively maintain the colonic mucus barrier and protect against spontaneous colitis in mice. Mucosal Immunol 2017:10:91-103.

67 Fu J, Wei B, Wen T, et al. Loss of intestinal core 1-derived 0-glycans causes spontaneous colitis in mice. J Clin Invest 2011;121:1657-66.

68 Meng Y, Li X, Zhang J, et al. Effects of different diets on microbiota in the small intestine mucus and weight regulation in rats. Sci Rep 2019:9:8500.

69 Rohr MW, Narasimhulu CA, Rudeski-Rohr TA, et al. Negative effects of a high-fat diet on intestinal permeability: a review. Adv Nutr 2020:11:77-91.

70 Araújo JR, Tomas J, Brenner C, et al. Impact of high-fat diet on the intestinal microbiota and small intestinal physiology before and after the onset of obesity. Biochimie 2017;141:97-106

71 Cani PD, Amar J, Iglesias MA, et al. Metabolic endotoxemia initiates obesity and insulin resistance. Ann Nutr Metab 2007;51:79.

72 Cani PD, Bibiloni R, Knauf C, et al. Changes in gut microbiota control metabolic endotoxemia-induced inflammation in high-fat diet-induced obesity and diabetes in mice. Diabetes 2008;57:1470-81.

73 Cani PD. Gut microbiota - at the intersection of everything? Nat Rev Gastroenterol Hepatol 2017;14:321-2

74 Desai MS, Seekatz AM, Koropatkin NM, et al. A dietary Fiber-Deprived gut microbiota degrades the colonic mucus barrier and enhances pathogen susceptibility. Cell 2016:167:1339-53.

75 Earle KA, Billings $\mathrm{G}$, Sigal M, et al. Quantitative imaging of gut microbiota spatial organization. Cell Host Microbe 2015:18:478-88.

76 Chassaing B, Van de Wiele T, De Bodt J, et al. Dietary emulsifiers directly alter human microbiota composition and gene expression ex vivo potentiating intestinal inflammation. Gut 2017;66:1414-27.

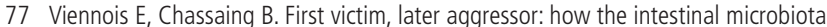
drives the pro-inflammatory effects of dietary emulsifiers? Gut Microbes 2018:9:289-91.

78 Chassaing B, Koren 0, Goodrich JK, et al. Dietary emulsifiers impact the mouse gut microbiota promoting colitis and metabolic syndrome. Nature 2015;519:92-6.

79 Cani PD. Dietary emulsifiers - sweepers of the gut lining? Nat Rev Endocrinol 2015;11:319-20.

80 Cani PD. Human gut microbiome: hopes, threats and promises. Gut 2018:67:1716-25.

81 Bron PA, Kleerebezem M, Brummer R-J, et al. Can probiotics modulate human disease by impacting intestinal barrier function? Br J Nutr 2017:117:93-107.

82 Sicard J-F, Le Bihan G, Vogeleer P, et al. Interactions of intestinal bacteria with components of the intestinal mucus. Front Cell Infect Microbiol $2017 ; 7: 387$ 
83 Schroeder BO, Birchenough GMH, Ståhlman M, et al. Bifidobacteria or fiber protects against diet-induced Microbiota-Mediated colonic mucus deterioration. Cell Host Microbe 2018;23:27-40.

84 Ahl D, Liu H, Schreiber O, et al. Lactobacillus reuteri increases mucus thickness and ameliorates dextran sulphate sodium-induced colitis in mice. Acta Physiologica 2016;217:300-10

85 Shin N-R, Lee J-C, Lee H-Y, et al. An increase in the Akkermansia spp. population induced by metformin treatment improves glucose homeostasis in diet-induced obese mice. Gut 2014;63:727-35.

86 Wu W, Lv L, Shi D, et al. Protective effect of Akkermansia muciniphila against immunemediated liver injury in a mouse model. Front Microbiol 2017;8:1804.

87 van der Lugt B, van Beek AA, Aalvink S, et al. Akkermansia muciniphila ameliorates the age-related decline in colonic mucus thickness and attenuates immune activation in accelerated aging Ercc1-/ $\Delta 7$ mice. Immun Ageing 2019;16:6.

88 Bárcena C, Valdés-Mas R, Mayoral P, et al. Healthspan and lifespan extension by fecal microbiota transplantation into progeroid mice. Nat Med 2019;25:1234-42.
89 Plovier H, Everard A, Druart C, et al. A purified membrane protein from Akkermansia muciniphila or the pasteurized bacterium improves metabolism in obese and diabetic mice. Nat Med 2017;23:107-13.

90 Dao MC, Everard A, Aron-Wisnewsky J, et al. Akkermansia muciniphila and improved metabolic health during a dietary intervention in obesity: relationship with gut microbiome richness and ecology. Gut 2016:65:426-36.

91 Depommier C, Everard A, Druart C, et al. Supplementation with Akkermansia muciniphila in overweight and obese human volunteers: a proof-of-concept exploratory study. Nat Med 2019;25:1096-103.

92 Willemsen LEM, Koetsier MA, van Deventer SJ. Short chain fatty acids stimulate epithelial mucin 2 expression through differential effects on prostaglandin E1 and E2 production by intestinal myofibroblasts. Gut 2003;52:1442-7.

93 Barcelo A, Claustre J, Moro F. Mucin secretion is modulated by luminal factors in the isolated vascularly perfused rat colon. Gut 2000;46:218-24.

94 Smirnova MG, Guo L, Birchall JP, et al. LPS up-regulates mucin and cytokine mRNA expression and stimulates mucin and cytokine secretion in goblet cells. Cell Immunol 2003;221:42-9. 